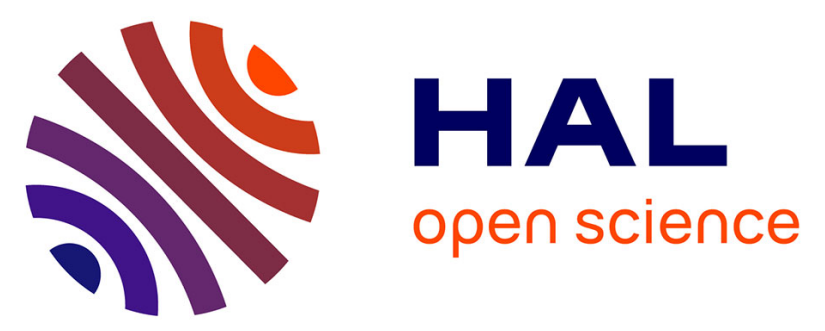

\title{
Determinants of benzodiazepine use in a representative population of HIV infected individuals: the role of HIV status disclosure (ANRS-EN12-VESPA study)
}

Perrine Roux, Lionel Fugon, Laurent Michel, France Lert, Yolande Obadia, Bruno Spire, P. Carrieri

\section{To cite this version:}

Perrine Roux, Lionel Fugon, Laurent Michel, France Lert, Yolande Obadia, et al.. Determinants of benzodiazepine use in a representative population of HIV infected individuals: the role of HIV status disclosure (ANRS-EN12-VESPA study). AIDS Care, 2011, pp.1. 10.1080/09540121.2011.555738 . hal-00701861

\section{HAL Id: hal-00701861 \\ https://hal.science/hal-00701861}

Submitted on 27 May 2012

HAL is a multi-disciplinary open access archive for the deposit and dissemination of scientific research documents, whether they are published or not. The documents may come from teaching and research institutions in France or abroad, or from public or private research centers.
L'archive ouverte pluridisciplinaire $\mathbf{H A L}$, est destinée au dépôt et à la diffusion de documents scientifiques de niveau recherche, publiés ou non, émanant des établissements d'enseignement et de recherche français ou étrangers, des laboratoires publics ou privés. 

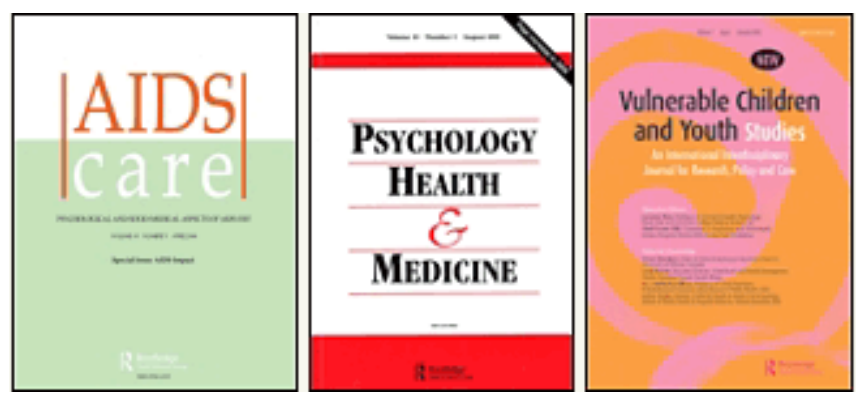

\section{Determinants of benzodiazepine use in a representative population of HIV infected individuals: the role of HIV status disclosure (ANRS-EN12-VESPA study)}

\begin{tabular}{|r|l|}
\hline Journal: & $\begin{array}{l}\text { AIDS Care - Psychology, Health \& Medicine - Vulnerable Children } \\
\text { and Youth Studies }\end{array}$ \\
\hline Manuscript ID: & AC-2010-04-0211.R2 \\
\hline Journal Selection: & AIDS Care \\
\hline Keywords: & disclosure, benzodiazepine, anxiety, HIV, stigma \\
\hline \multicolumn{2}{|l}{} \\
\hline
\end{tabular}




\section{Determinants of benzodiazepine use in a representative population of HIV infected} individuals: the role of HIV status disclosure (ANRS-EN12-VESPA study)

ROUX Perrine ${ }^{1,2,3}$, FUGON Lionel ${ }^{1,2,3}$, MICHEL Laurent ${ }^{4,5}$, LERT France ${ }^{6}$, OBADIA Yolande $^{1,2,3}$, SPIRE Bruno ${ }^{1,2,3}$, CARRIERI Maria Patrizia ${ }^{1,2,3}$

${ }^{1}$ INSERM, U912 (SE4S), Marseille, France

${ }^{2}$ Université Aix Marseille, IRD, UMR-S912, Marseille, France

${ }^{3}$ ORS PACA, Observatoire Régional de la Santé Provence Alpes Côte d'Azur, Marseille, France

${ }^{4}$ Centre de Traitement des Addictions, Hôpital Emile Roux, Limeil-Brévannes, France

${ }^{5}$ Université Paris-Sud, Université Paris Descartes, UMR-S0669, Paris

${ }^{6}$ INSERM U687-IFR 69, Saint-Maurice, France

Corresponding author: Dr Perrine ROUX

Address : ORS PACA/InsermU912, 23 rue Stanislas Torrents, 13006 Marseille, France

Phone: 0033(0)496102876, Fax: 0033(0)496102899,E-mail: perrine.roux@inserm.fr

Word count : 3073

This study was supported by the French National Agency of AIDS and Hepatitis Research (ANRS, France). Special thanks to the members of the VESPA Group: C. Afsa (INSEE), A. Bonnet (UFR Psychopathologie, Université de Provence), A.D. Bouhnik (INSERM U912/ORS PACA), V. Di Paola (LEST), R. Dray-Spira (INSERM U88), J. Fagnani (CNRS-UMR Matisse), L. Fernandez (UFR Psychopathologie, Université de Provence), I. Heard (INSERM U430), F. Lert (INSERM U88), Y. Obadia (ORS PACA/INSERM U912), J.L. Pedinielli (UFR Psychopathologie, Université de Provence), P. Peretti-Watel (ORS PACA/INSERM U912), J. Pierret (CERMES-INSERM U504-UMR 8559), B. Riandey (INED), M.A. Schiltz (CERMES-INSERM U504-UMR 8559), R. Sitta (INSERM U88), and B. Spire (INSERM U912/ORSPACA). 


\section{Abstract}

Objective: HIV infection may result in stressful situations such as disclosure to others and could be a mediator between seropositivity status and psychiatric illness, depression or anxiety. Several results have shown that anxiolytic use (mainly benzodiazepines) is highly prevalent in HIV-infected individuals, but few studies have highlighted to what extent this use could be associated with HIV disclosure. Design: A national cross-sectional survey representative of people living with HIV and AIDS in France enrolled 2932 individuals in 102 French HIV hospital departments. Methods: Face-to-face interviews and self-administered questions collected information about patients' experience with HIV and HIV care, including use of psychotropic drugs, social support, stigma and disclosure of HIV status. We identified factors associated with regular BDZ use (i.e. more than once a week) using a weighted logistic regression model. Results: Regular BDZ use and anxiety symptoms were reported by $16 \%$ and $29 \%$ of the patients respectively. After multiple adjustment for known correlates of BDZ use and anxiety symptoms, individuals who had disclosed their HIV status to relatives or friends were found to be more likely $(\mathrm{OR}[95 \% \mathrm{Cl}]=1.78[1.02-3.09])$ to regularly use $\mathrm{BDZ}$. Conclusions: These results show both to what extent disclosure to others continues to be a stressful step in the course of HIV infection and that disclosure is something which could be identified by BDZ use. They also highlight the need for appropriate case management and psychiatric care to help patients manage the consequences of disclosure.

Words: 239 


\section{Introduction}

Mood and anxiety disorders are known to be highly prevalent in HIV infected individuals (Bing, et al., 2001; Silverman, 1993) and are of great concern because of their impact on HIV care effectiveness (Whetten, Reif, Whetten, \& Murphy-McMillan, 2008). Depressive symptoms have been widely recognized as a determinant of non-adherence to ART (Starace, et al., 2002) and are found to impair virological suppression in patients receiving ART (Villes, et al., 2007). Anxiety symptoms have been investigated to a lesser extent (e.g. (Chander, Himelhoch, \& Moore, 2006)) despite evidence about their negative impact on health outcomes in the HIV positive population (Campos, Guimaraes, \& Remien, 2010; Roux, et al., 2009). Anxiety symptoms are core symptoms of different disorders, including generalized anxiety disorder, social phobia, agoraphobia, panic attacks, obsessive-compulsive disorder and post-traumatic stress disorder (Roy-Byrne, et al., 2010). They are also present for those with depression, often being even more prominent than depressive symptoms, and therefore giving rise to the diagnosis of "anxious depression" (Nelson, 2008). However, anxiety symptoms may also occur in reaction to stressful situations, as is the case for example during the course of HIV infection, especially with regard to its psycho-social burden (Gonzalez, Solomon, Zvolensky, \& Miller, 2009), e.g. reduced social support, financial insecurity and stigmatization (Bravo, Edwards, Rollnick, \& Elwyn, 2010; Michels \& Marzuk, 1993). This may also be the case following HIV disclosure to relatives and friends (Golub, Tomassilli, \& Parsons, 2009). While some studies have shown that living with the HIV secret may be 
more emotionally harmful than the stigma resulting from disclosure, this latter may nonetheless be seen as a stressful event (Gielen, O'Campo, Faden, \& Eke, 1997). The study conducted by Niccolai et al. on disclosure of HIV serostatus to sex partners showed that non-disclosure is often underestimated and is motivated by the fear of negative consequences (Niccolai, King, D'Entremont, \& Pritchett, 2006). Our hypothesis is based on the theory described by Hatzenbuehler that HIV serostatus disclosure may increase exposure to stress resulting from stigma (Hatzenbuehler, 2009). This stigma related stress may result in anxiety-like reactions such as the taking of anxiolytics. A recent article shows that in France benzodiazepines are widely abused (Pradel, Delga, Rouby, Micallef, \& Lapeyre-Mestre, 2010) and prescribed despite their poor benefit/risk ratio for most anxiety disorders (Pelissolo, et al., 2007) and for major depressive disorders (Davidson, 2010). As previously seen, anxiety symptoms feature in several diagnoses of anxiety or depressive disorders. Their prevalence is high during chronic illnesses (Filipcic, et al., 2007), especially among HIV-infected patients, and they are often determined by the specific medical condition together with environmental factors and psychological traits. Assessing the use of BDZ would therefore appear to be of clinical relevance as it may be an indicator of exposure to stressful events, such as discrimination, which are not always easy to disclose to one's physician. The Vespa survey, a national cross-sectional study, conducted in France in a representative sample of HIV infected individuals gave us the opportunity to study correlates, and more particularly the impact of HIV status disclosure on regular BDZ use. 


\section{Methods}

\section{Study design}

The ANRS-EN12-VESPA study was supported by the French National Agency of AIDS and Hepatitis Research (ANRS) and consisted of a national cross-sectional survey conducted in 2003 among a random sample of 4,963 HIV-infected patients recruited in 102 French hospital departments delivering HIV care. The sample was stratified according to each department's geographic location and HIV caseload (Peretti-Watel, et al., 2005). Eligible subjects were French speaking outpatients diagnosed with HIV-infection for at least 6 months, aged 18 or older, and living in France for at least 6 months. Each patient interview lasted on average 40 minutes. When the interview ended, if the patient had been deemed eligible for study participation, he/she was consulted by the physician. Patients who agreed to participate signed a letter of informed consent and answered a face-to-face questionnaire administered by a trained interviewer with the CAPI system (Computer Assisted Personal Interview). As patients who attended outpatient clinics were overrepresented more frequently, the sample was weighted by the inverse of patients' annual number of visits in the clinic (since the probability of being asked to participate was proportional to this number).

\section{Study population}

Among the eligible patients in the Vespa study, 2932 agreed to participate, 1767 refused and 264 were not solicited as their physician considered that their physical or 
psychological conditions were not compatible with participation in the survey. Nonrespondents were not significantly different from respondents in terms of gender, age, viral load or CD4 lymphocyte count. Of the 2932 participants, 667 (22.7\%) did not answer the Hospital Anxiety and Depression scale (HADS) questions, included in the study. We therefore restricted our analysis to 2265 (77.3\%) respondents. After conducting a sensitivity analysis between respondents (i.e. those who answered the HADS questions) and non-respondents, no significant differences were observed between both groups in terms of age, undetectable viral load, HIV clinical stage, ART receipt and $\mathrm{BDZ}$ use.

\section{Data collection}

The questionnaire comprised approximately 400 questions in 10 modules, but only a subset of these has been used in the present article. One section of the questionnaire collected socio-demographic information about gender, age, origin (i.e. being born outside of France or not), living in a couple or not, educational level, employment and various life events including experience of discrimination, incarceration, prostitution, suicide attempts and HIV status disclosure to someone including relatives, friends or others.

Another section of the questionnaire focused on HIV medical information such as time since HIV diagnosis, receiving ART or not, self-reported side-effects and finally, transmission group (injecting drug use (IDU), men who have sex with men (MSM), and heterosexual contact). The prevalence of anxiety and depression were assessed using 
the HADS, which is a 14-item self-rating instrument ( 7 items relating to anxiety and 7 to depression) on a 4-point Likert scale, assessing individuals' experiences over the previous week. For each subscale (anxiety or depression), the score is the sum of the respective items (ranging from 0-21). In clinical practice, individuals are considered as follows: not clinically depressed/anxious if their total score for each HADS subscale lies between 0 and 7, borderline depressed/anxious for scores between 8 and 10, and clinically depressed/anxious for scores of 11 or more. In our analysis, we chose to use these three categories to define anxiety symptoms (Thomas, et al., 2005).

Information regarding alcohol abuse was collected using the CAGE questionnaire based on four items (Malet, Schwan, Boussiron, Aublet-Cuvelier, \& Llorca, 2005). Consumption of psychotropic medications (antidepressants, hypnotics and anxiolytics such as benzodiazepines) was reported by patients and documented by recording the frequency of consumption during the previous 4 weeks, in a medical or non-medical context. The different frequencies of use were: "never (no use)", "less than once a week", "once a week", "several times a week", and "daily or almost daily". These possibilities were applied to a list of benzodiazepines (alprazolam, bromazepam, clobazam, clorazepate, diazepam, flunitrazepam, loprazolam, oxazepam, prazepam). For this study, we classified those whose frequency was "once a week", "several times on a week" and "daily or almost daily" as regular consumers of benzodiazepines and moderate/nonconsumers for those whose frequency was "never" or "less than once a week". The outcome variable was then dichotomized according to these two groups. 
A dichotomized indicator of HIV disclosure (Yes or No) was constructed using data from a set of questions about HIV disclosure. The main question asked was the following: "Have you told anyone about your infection since becoming aware of it and when?". For each relative (e.g. father, mother, sibling, other relative) and friend, participants had to choose one answer from the following possibilities:

(1) "Yes, immediately when I was informed of my infection", (2)“Yes, during hospital stay", (3) “Yes, at treatment initiation”, (4)“Yes, on another occasion”, (5)“No, she/he doesn't know”, (6)“No, but she/he discovered it from someone else”, (7)“I don't know if she/he knows", (8)“Non-applicable”, (9)" I refuse to answer". Participants who chose answer (1), (2), (3), (4) or (6), were considered to have disclosed their HIV serostatus. When a patient answered (5), (7) or (8), he/she was considered to have declared nondisclosure. Answer (9) was considered as missing data.

\section{Statistical Analysis}

Risk factors and other explanatory variables were screened for inclusion in the model by testing each independently for a significant association with regular benzodiazepine use, using weighted univariate logistic regression. Variables which achieved a liberal significance level of $/ \mathrm{P} / \leq 0.20$ in the univariate analysis were included in the multivariate model. The final multivariate model was built using a backward elimination approach based on the log-likelihood ratio $(p<1 \leq 0.05)$. A receiver operating characteristic (ROC) curve was used to assess the logistic regression model's ability to 
accurately distinguish individuals who regularly used benzodiazepines from all the others.

The area under the ROC curve $(A \cup C)$ provides a measure of discrimination (Hosmer \& Lemeshow, 2000): when $0.7 \leq \mathrm{AUC}<0.8$ the discrimination power is considered to be satisfactory. Data management and statistical analyses were performed using SPSS v15.0 software (SPSS Inc., Chicago, IL, USA).

\section{$\underline{\text { Results }}$}

Socio-demographic and behavioral characteristics on 2265 patients are presented in Table 1. The whole sample comprised 604 (27\%) women and median [IQR] age was $41[36 ; 47]$ years. Nearly one third of the patients had a secondary school certificate and more than half (59\%) had a job. Migrants represented 366 individuals, corresponding to $16 \%$ of the sample.

With regard to negative life events, 39\% patients reported suffering from discrimination, one fifth (22\%) of the patients reported attempting suicide and nearly one patient in eight (11\%) had never disclosed their HIV status to anyone.

With respect to medical characteristics, 762 (32\%) patients had been HIV-infected by heterosexual contact, 1003 (47\%) by homosexual contact and $377(17 \%)$ by intravenous drug use. The median time since HIV diagnosis was $9[5 ; 14]$ years. Most individuals (80\%) were receiving ART and nearly one quarter (24\%) reported perceiving side-effects at the time of the study. Twenty-two percent of the patients (495) were classified with 
HIV clinical stage $\mathrm{C}$ and $68 \%$ had an undetectable viral load. Anxiety and depressive symptoms (corresponding to a HADS score greater than 11) were found respectively in 667 (29\%) patients and 215 patients (10\%). The Cronbach's alpha coefficient was 0.80 for anxiety and 0.82 for depression.

Alcohol abuse was identified in 301 (13\%) individuals using the CAGE score. With regard to the use of psychotropics during the previous month, $356(16 \%)$ reported regular benzodiazepine consumption while 215 (9\%) reported antidepressant use during the previous 4 weeks.

Univariate analysis (Table 1) showed that several variables were determinants of regular BDZ use. In regard to socio-demographic factors, individuals with no employment or no secondary school certificate were more likely to use BDZ regularly. Not surprisingly, this was also found for individuals who presented certain characteristics related to drug use or psychiatric illnesses (IDU HIV transmission group, alcohol abuse, antidepressants use, anxiety symptoms). Many variables relating to negative life events, such as discrimination or suicide attempts, were found to be significantly associated with the outcome. With respect to HIV-related factors, we found that individuals who had disclosed their HIV serostatus, those not receiving ART, those with HIV clinical stage C and those who perceived self-reported symptoms were more likely to use BDZ.

In multivariate analysis (Table 2), one interesting result is that HIV status disclosure remained associated with regular BDZ use (OR $[95 \% \mathrm{Cl}]=1.78[1.02-3.09])$. To confirm our 
hypothesis, we adjusted for some eligible factors such as older age, living in a couple, diagnosis of HIV clinical stage C, reporting anxiety symptoms $(\mathrm{OR}[95 \% \mathrm{Cl}]=6.02[4.39$ 8.26]) or a history of suicide attempts and finally belonging to the IDU or MSM HIV transmission group. It is important to note that patients who had depressive symptoms were not more likely to be regular BDZ users. Another interesting factor associated with regular BDZ consumption was that of being a "migrant" (i.e. being born outside of France). A bivariate analysis showed that migrants were less likely to disclose their HIV status. We also evaluated the discriminatory performance of the final statistical model; the area under the ROC Curve was 0.74 with a 95\% confidence interval [0.72-0.77], which is an acceptable discrimination according to Hosmer and Lemeshow.

\section{Discussion}

This study provides novel results about the prevalence and the correlates of regular benzodiazepine (BDZ) use in a representative sample of HIV-infected individuals in France.

First, we identified known correlates deserving further investigation in terms of improving the clinical evaluation of BDZ use, something which is desirable for several reasons. To begin with, its regular use is known to induce dependence and cognitive impairment (Barker, Greenwood, Jackson, \& Crowe, 2004). Although access to anxiolytics was found to be associated with higher adherence to ART for women in this same VESPA survey (Roux, et al., 2009), other studies have highlighted that cognitive 
impairment is a determinant of non-adherence to ART (Carballo, et al., 2004; Hinkin, et al., 2004). In addition, as many other findings have already shown, BDZ abuse is responsible for many side effects (Chouinard, 2004) and should be taken into account when considering drug-drug interaction in ART treated patients (Greenblatt, von Moltke, Daily, Harmatz, \& Shader, 1999).

Second, HIV disclosure to relatives or friends was significantly associated with regular BDZ use (although this association was not as strong as that found for the other variables). As for a series of other stressful situations, this association has consistently been found in the literature (Niccolai, et al., 2006). We found that most of the patients (89\%) had already disclosed their HIV status to a relative or a friend confirming that HIVinfected individuals need to cope with the disclosure of their infection to someone during the course of HIV disease (Feskanich, et al., 2002). It is known that HIV status disclosure is underestimated and consequently deserves investigation, particularly in clinical practice. The findings in this paper might well encourage physicians to investigate more thoroughly what psycho-social factors lie behind the use of BDZ. As it is very difficult for an HIV physician to directly tackle exposure to stigma during face-toface interviews, discussing the patient's use of anxiolytics (more frequently prescribed by primary care physicians) could provide an indication of the level of difficulty patients face when coping with stressful situations. Moreover, speaking about anxiolytics' effectiveness could provide an opportunity for the patient to talk about the context of social situations which generate anxiety symptoms. Therefore, providing patients with both social and psychological follow-up may help achieve early detection and better 
management of stressful situations. Indeed, the fact that disclosure of HIV status to relatives or friends was associated with regular BDZ use supports the conclusion of Petrak et al. suggesting that reasons for non-disclosure include the desire to protect others from distress and fear of discrimination (Petrak, Doyle, Smith, Skinner, \& Hedge, 2001). It is also known that willingness to disclose is negatively associated with HIVrelated stigma (Yang, Li, et al., 2006) which may be a cause of anxiety (Golub, Tomassilli, \& Parsons, 2009). Although patients need to disclose their HIV-positive status in order to receive specific advice, emotional support and information, disclosure of one's HIV infection may nonetheless be considered as a traumatic event at the origin for anxiety symptoms (Siegel, Lekas, \& Schrimshaw, 2005).

As in other studies, we found that certain socio-demographic characteristics, such as older age, unemployment and not living in a couple were significantly associated with the outcome. As expected, patients who were affected by anxiety symptoms were more likely to regularly use BDZ (Demyttenaere, et al., 2008). Some previous findings have already shown that older HIV infected patients experience a greater number of psychiatric comorbidities, including anxiety symptoms and sleep disorders (Kilbourne, Justice, Rabeneck, Rodriguez-Barradas, \& Weissman, 2001).

In addition, our results suggest that certain indicators of positive social functioning, such as having employment and living in a couple, are associated with less frequent BDZ use. This is consistent with findings from many other studies which have suggested that receiving social support is associated with reduced emotional distress and consequently 
reduced BZD consumption (Serovich, Kimberly, Mosack, \& Lewis, 2001). Conversely, having less social contact has been found to be a high risk factor for anxiety in elderly patients (Majercsik \& Haller, 2004). Moreover, alcohol abuse and BDZ dependence are known to be intimately correlated (Ashton, 2005) and early BDZ treatment may bring about alcohol dependence (Martijena, Lacerra, Bustos, \& Molina, 2001).

With regard to medical characteristics, individuals with clinical stage C (i.e. who had experienced clinical progression to AIDS) were more likely to regularly use BDZ. This is perhaps because, in general, experience of clinical progression is accompanied by stress (Kalichman, Difonzo, Austin, Luke, \& Rompa, 2002) and the difficulty to hide one's HIV status.

Migrants were less likely to regularly use BDZ and were also more likely to conceal their HIV status. These results are consistent with those in previous studies showing that fear of discrimination and stigma is very prevalent in the migrant community (Fakoya, Reynolds, Caswell, \& Shiripinda, 2008).

On the contrary, we found that individuals belonging to MSM or IDU HIV transmission groups were more likely to report regular benzodiazepine use. Indeed, these groups often face and perceive more discrimination and stigmatization than heterosexual HIVinfected individuals (Herek, Capitanio, \& Widaman, 2003).

Benzodiazepine use has been found to be associated with a history of suicide attempts even after adjustment for anxiety and depressive symptoms. Even though no association was found between benzodiazepine use and depressive symptoms in this 
study, a history of suicide attempts may be considered as an indicator of previous psychiatric comorbidities, such as major depression (Horesh, Sever, \& Apter, 2003) or negative life events and discrimination (Preau, Bouhnik, Peretti-Watel, Obadia, \& Spire, 2008).

Some limitations of the study have to be acknowledged. Although the HADS is a common and convenient instrument to measure depression and anxiety symptoms in patients with both somatic and mental problems in the general population (Mykletun, Stordal, \& Dahl, 2001), it is not recognized as being the most relevant system to use for those suffering from major depression (Bunevicius, Peceliuniene, Mickuviene, Valius, \& Bunevicius, 2007). That is why the correct diagnosis of major depression, which is imperative in clinical practice, needs a more adapted tool in the research context. Moreover, it is difficult to find the causality between disclosure and BDZ use and this issue needs to be investigated more thoroughly. Despite this weakness, one of the major strengths of this study is that it is based on a large representative sample of HIV infected individuals - through homosexual or heterosexual contact or through injecting drug use (IDU) - receiving HAART in a representative sample of hospitals with HIV care services.

Our findings underline several issues that require further investigation. First, treatment for anxiety and mood disorders in France, which is often managed in primary care, leaves much to be desired in the context of the country's HIV population. Though it has already been shown that integrating mental health services into HIV primary care is 
necessary in order to help vulnerable populations manage HIV infection and precariousness, screening for anxiety disorders as well as their management in primary care may present many weaknesses (Weisberg, Dyck, Culpepper, \& Keller, 2007). Furthermore, time of disclosure should be considered as a special step in the course of HIV infection. More than improving screening for psychiatric symptoms and adapting care to deal with anxiety symptoms, it is important to implement specific follow-up procedures at the time of HIV status disclosure. HIV infection still raises a lot of concern in terms of stigmatization and while waiting for this factor to be fully tackled in HIV prevention and follow-up care models, HIV infected persons need careful attention and adequate care through a patient-centered approach.

\section{References}

Ashton, H. (2005). The diagnosis and management of benzodiazepine dependence. Curr Opin Psychiatry, 18(3), 249-255.

Barker, M.J., Greenwood, K.M., Jackson, M., \& Crowe, S.F. (2004). Persistence of cognitive effects after withdrawal from long-term benzodiazepine use: a meta-analysis. Arch Clin Neuropsychol, 19(3), 437-454.

Bing, E.G., Burnam, M.A., Longshore, D., Fleishman, J.A., Sherbourne, C.D., London, A.S., Turner, B.J., Eggan, F., Beckman, R., Vitiello, B., Morton, S.C., Orlando, M., Bozzette, S.A., OrtizBarron, L., \& Shapiro, M. (2001). Psychiatric disorders and drug use among human immunodeficiency virus-infected adults in the United States. Arch Gen Psychiatry, 58(8), 721-728.

Bravo, P., Edwards, A., Rollnick, S., \& Elwyn, G. (2010). Tough decisions faced by people living with HIV: a literature review of psychosocial problems. AIDS Rev, 12(2), 76-88.

Bunevicius, A., Peceliuniene, J., Mickuviene, N., Valius, L., \& Bunevicius, R. (2007). Screening for depression and anxiety disorders in primary care patients. Depress Anxiety, 24(7), 455460.

Campos, L.N., Guimaraes, M.D., \& Remien, R.H. (2010). Anxiety and depression symptoms as risk factors for non-adherence to antiretroviral therapy in Brazil. AIDS Behav, 14(2), 289-299.

Carballo, E., Cadarso-Suarez, C., Carrera, I., Fraga, J., de la Fuente, J., Ocampo, A., Ojea, R., \& Prieto, A. (2004). Assessing relationships between health-related quality of life and adherence to antiretroviral therapy. Qual Life Res, 13(3), 587-599. 
Chander, G., Himelhoch, S., \& Moore, R.D. (2006). Substance abuse and psychiatric disorders in HIV-positive patients: epidemiology and impact on antiretroviral therapy. Drugs, 66(6), 769-789.

Chouinard, G. (2004). Issues in the clinical use of benzodiazepines: potency, withdrawal, and rebound. J Clin Psychiatry, 65 Suppl 5, 7-12.

Davidson, J.R. (2010). Major depressive disorder treatment guidelines in America and Europe. J Clin Psychiatry, 71 Suppl E1, e04.

Demyttenaere, K., Bonnewyn, A., Bruffaerts, R., De Girolamo, G., Gasquet, I., Kovess, V., Haro, J.M., \& Alonso, J. (2008). Clinical factors influencing the prescription of antidepressants and benzodiazepines: results from the European study of the epidemiology of mental disorders (ESEMeD). J Affect Disord, 110(1-2), 84-93.

Fakoya, I., Reynolds, R., Caswell, G., \& Shiripinda, I. (2008). Barriers to HIV testing for migrant black Africans in Western Europe. HIV Med, 9 Suppl 2, 23-25.

Feskanich, D., Hastrup, J.L., Marshall, J.R., Colditz, G.A., Stampfer, M.J., Willett, W.C., \& Kawachi, I. (2002). Stress and suicide in the Nurses' Health Study. J Epidemiol Community Health, 56(2), 95-98.

Filipcic, I., Popovic-Grle, S., Marcinko, D., Basic, S., Hotujac, L., Pavicic, F., Hajnaek, S., \& Aganovic, I. (2007). Screening for depression disorders in patients with chronic somatic illness. Coll Antropol, 31(1), 139-143.

Gielen, A.C., O'Campo, P., Faden, R.R., \& Eke, A. (1997). Women's disclosure of HIV status: experiences of mistreatment and violence in an urban setting. Women Health, 25(3), 1931.

Golub, S.A., Tomassilli, J.C., \& Parsons, J.T. (2009). Partner serostatus and disclosure stigma: implications for physical and mental health outcomes among HIV-positive adults. AIDS Behav, 13(6), 1233-1240.

Gonzalez, A., Solomon, S.E., Zvolensky, M.J., \& Miller, C.T. (2009). The interaction of mindfulbased attention and awareness and disengagement coping with HIV/AIDS-related stigma in regard to concurrent anxiety and depressive symptoms among adults with HIV/AIDS. J Health Psychol, 14(3), 403-413.

Greenblatt, D.J., von Moltke, L.L., Daily, J.P., Harmatz, J.S., \& Shader, R.I. (1999). Extensive impairment of triazolam and alprazolam clearance by short-term low-dose ritonavir: the clinical dilemma of concurrent inhibition and induction. J Clin Psychopharmacol, 19(4), 293-296.

Hatzenbuehler, M.L. (2009). How does sexual minority stigma "get under the skin"? A psychological mediation framework. Psychol Bull, 135(5), 707-730.

Herek, G.M., Capitanio, J.P., \& Widaman, K.F. (2003). Stigma, social risk, and health policy: public attitudes toward HIV surveillance policies and the social construction of illness. Health Psychol, 22(5), 533-540.

Hinkin, C.H., Hardy, D.J., Mason, K.I., Castellon, S.A., Durvasula, R.S., Lam, M.N., \& Stefaniak, M. (2004). Medication adherence in HIV-infected adults: effect of patient age, cognitive status, and substance abuse. Aids, 18 Suppl 1, S19-25.

Horesh, N., Sever, J., \& Apter, A. (2003). A comparison of life events between suicidal adolescents with major depression and borderline personality disorder. Compr Psychiatry, 44(4), 277-283.

Hosmer, D.W., \& Lemeshow, S. (2000). Applied logistic regression (p. 392 pages): Wiley.

Kalichman, S.C., Difonzo, K., Austin, J., Luke, W., \& Rompa, D. (2002). Prospective study of emotional reactions to changes in HIV viral load. AIDS Patient Care STDS, 16(3), 113-120. 
Kilbourne, A.M., Justice, A.C., Rabeneck, L., Rodriguez-Barradas, M., \& Weissman, S. (2001). General medical and psychiatric comorbidity among HIV-infected veterans in the postHAART era. J Clin Epidemiol, 54 Suppl 1, S22-28.

Majercsik, E., \& Haller, J. (2004). Interactions between anxiety, social support, health status and buspirone efficacy in elderly patients. Prog Neuropsychopharmacol Biol Psychiatry, 28(7), 1161-1169.

Malet, L., Schwan, R., Boussiron, D., Aublet-Cuvelier, B., \& Llorca, P.M. (2005). Validity of the CAGE questionnaire in hospital. Eur Psychiatry, 20(7), 484-489.

Martijena, I.D., Lacerra, C., Bustos, S.G., \& Molina, V.A. (2001). Chronic benzodiazepine administration facilitates the subsequent development of ethanol dependence. Brain Res, 891(1-2), 236-246.

Michels, R., \& Marzuk, P.M. (1993). Progress in psychiatry (2). N Engl J Med, 329(9), 628-638.

Mykletun, A., Stordal, E., \& Dahl, A.A. (2001). Hospital Anxiety and Depression (HAD) scale: factor structure, item analyses and internal consistency in a large population. $\mathrm{Br} J$ Psychiatry, 179, 540-544.

Nelson, J.C. (2008). Anxious depression and response to treatment. Am J Psychiatry, 165(3), 297299.

Niccolai, L.M., King, E., D'Entremont, D., \& Pritchett, E.N. (2006). Disclosure of HIV serostatus to sex partners: a new approach to measurement. Sex Transm Dis, 33(2), 102-105.

Pelissolo, A., Maniere, F., Boutges, B., Allouche, M., Richard-Berthe, C., \& Corruble, E. (2007). [Anxiety and depressive disorders in 4,425 long term benzodiazepine users in general practice]. Encephale, 33(1), 32-38.

Peretti-Watel, P., Riandey, B., Dray-Spira, R., Bouhnik, A.D., Sitta, R., \& Obadia, Y. (2005). Comment enquêter la population séropositive en France ? L'enquête ANRS-EN12-VESPA 2003. Population, 60(4), 525-550.

Petrak, J.A., Doyle, A.M., Smith, A., Skinner, C., \& Hedge, B. (2001). Factors associated with selfdisclosure of HIV serostatus to significant others. Br J Health Psychol, 6(Pt 1), 69-79.

Pradel, V., Delga, C., Rouby, F., Micallef, J., \& Lapeyre-Mestre, M. (2010). Assessment of abuse potential of benzodiazepines from a prescription database using 'doctor shopping' as an indicator. CNS Drugs, 24(7), 611-620.

Preau, M., Bouhnik, A.D., Peretti-Watel, P., Obadia, Y., \& Spire, B. (2008). Suicide attempts among people living with HIV in France. AIDS Care, 20(8), 917-924.

Roux, P., Carrieri, M.P., Michel, L., Fugon, L., Marcellin, F., Obadia, Y., \& Spire, B. (2009). Effect of anxiety symptoms on adherence to highly active antiretroviral therapy in HIV-infected women. J Clin Psychiatry, 70(9), 1328-1329.

Roy-Byrne, P., Craske, M.G., Sullivan, G., Rose, R.D., Edlund, M.J., Lang, A.J., Bystritsky, A., Welch, S.S., Chavira, D.A., Golinelli, D., Campbell-Sills, L., Sherbourne, C.D., \& Stein, M.B. (2010). Delivery of evidence-based treatment for multiple anxiety disorders in primary care: a randomized controlled trial. Jama, 303(19), 1921-1928.

Serovich, J.M., Kimberly, J.A., Mosack, K.E., \& Lewis, T.L. (2001). The role of family and friend social support in reducing emotional distress among HIV-positive women. AIDS Care, 13(3), 335-341.

Siegel, K., Lekas, H.M., \& Schrimshaw, E.W. (2005). Serostatus disclosure to sexual partners by HIV-infected women before and after the advent of HAART. Women Health, 41(4), 6385.

Silverman, D.C. (1993). Psychosocial impact of HIV-related caregiving on health providers: a review and recommendations for the role of psychiatry. Am J Psychiatry, 150(5), 705712. 
Starace, F., Ammassari, A., Trotta, M.P., Murri, R., De Longis, P., Izzo, C., Scalzini, A., d'Arminio Monforte, A., Wu, A.W., \& Antinori, A. (2002). Depression is a risk factor for suboptimal adherence to highly active antiretroviral therapy. J Acquir Immune Defic Syndr, 31 Suppl 3, S136-139.

Thomas, B.C., Devi, N., Sarita, G.P., Rita, K., Ramdas, K., Hussain, B.M., Rejnish, R., \& Pandey, M. (2005). Reliability \& validity of the Malayalam hospital anxiety \& depression scale (HADS) in cancer patients. Indian J Med Res, 122(5), 395-399.

Villes, V., Spire, B., Lewden, C., Perronne, C., Besnier, J.M., Garre, M., Chene, G., Leport, C., Carrieri, M.P., \& Le Moings, V. (2007). The effect of depressive symptoms at ART initiation on HIV clinical progression and mortality: implications in clinical practice. Antivir Ther, 12(7), 1067-1074.

Weisberg, R.B., Dyck, I., Culpepper, L., \& Keller, M.B. (2007). Psychiatric treatment in primary care patients with anxiety disorders: a comparison of care received from primary care providers and psychiatrists. Am J Psychiatry, 164(2), 276-282.

Whetten, K., Reif, S., Whetten, R., \& Murphy-McMillan, L.K. (2008). Trauma, mental health, distrust, and stigma among HIV-positive persons: implications for effective care. Psychosom Med, 70(5), 531-538.

Yang, H., Li, X., Stanton, B., Fang, X., Lin, D., \& Naar-King, S. (2006). HIV-related knowledge, stigma, and willingness to disclose: A mediation analysis. AIDS Care, 18(7), 717-724. 
Table 1. Factors associated with regular benzodiazepine use ${ }^{*}$ in HIV-infected individuals: Univariate analysis using logistic mixed models (VESPA survey, $\mathrm{N}=2265$ patients)

\begin{tabular}{|c|c|c|c|c|}
\hline & \multicolumn{4}{|c|}{ Univariate analysis } \\
\hline & \multicolumn{2}{|c|}{$\begin{array}{l}\text { No. of years/ } \\
\text { No. of patients }\end{array}$} & $\begin{array}{c}\text { OR } \\
(95 \% \mathrm{Cl})\end{array}$ & p-value \\
\hline & $\begin{array}{l}\text { Regular } \\
\text { BZD use }\end{array}$ & $\begin{array}{l}\text { Non regular } \\
\text { BZD use }\end{array}$ & & \\
\hline Age $(\text { Median }[I Q R])^{\mu}$ & $42[38-48]$ & $42[36-47]$ & $1.01[1-1.02]$ & 0.06 \\
\hline Female gender & $107(30)$ & $497(26)$ & $1.22[0.95-1.56]$ & 0.12 \\
\hline Living in a couple & $42(12)$ & $458(24)$ & $0.43[0.30-0.60]$ & $<0.001$ \\
\hline Secondary school certificate & $104(29)$ & $636(33)$ & $0.83[0.65-1.06]$ & 0.13 \\
\hline Employed & $169(47)$ & $1173(61)$ & $0.57[0.45-0.71]$ & $<0.001$ \\
\hline Migrant $\$$ & $37(11)$ & 329 (17) & $0.57[0.40-0.81]$ & 0.002 \\
\hline History of discrimination & $184(52)$ & $710(37)$ & $1.79[1.43-2.25]$ & $<0.001$ \\
\hline $\begin{array}{l}\text { HIV transmission group } \\
\text { Heterosexuals } \\
\text { MSM } \\
\text { IDUs }\end{array}$ & $\begin{array}{l}86(24) \\
159(45) \\
96(27)\end{array}$ & $\begin{array}{l}676(35) \\
844(44) \\
281(15)\end{array}$ & $\begin{array}{c}1 \\
1.49[1.13-1.98] \\
2.69[1.95-3.71]\end{array}$ & $\begin{array}{c}0.005 \\
<0.001\end{array}$ \\
\hline $\begin{array}{l}\text { Anxiety symptoms } \\
\text { not clinically anxious } \\
\text { borderline anxious } \\
\text { clinically anxious }\end{array}$ & $\begin{array}{l}71(20) \\
85(24) \\
200(56)\end{array}$ & $\begin{array}{l}971(50) \\
471(25) \\
467(25)\end{array}$ & $\begin{array}{c}1 \\
2.48[1.77-3.46] \\
5.85[4.37-7.84]\end{array}$ & $\begin{array}{l}<0.001 \\
<0.001\end{array}$ \\
\hline $\begin{array}{l}\text { Depression symptoms } \\
\text { not clinically depressive } \\
\text { borderline depressive } \\
\text { clinically depressive }\end{array}$ & $\begin{array}{l}215(61) \\
60(17) \\
74(21)\end{array}$ & $\begin{array}{c}1522(80) \\
221(12) \\
142(7)\end{array}$ & $\begin{array}{c}1 \\
1.94[1.41-2.66] \\
3.69[2.69-5.05]\end{array}$ & $\begin{array}{l}<0.001 \\
<0.001\end{array}$ \\
\hline Suicide attempts ${ }^{\S}$ & $123(35)$ & $384(20)$ & $2.09[1.63-2.67]$ & $<0.001$ \\
\hline Number of years since HIV diagnosis ${ }^{1}$ & $11[7-15]$ & $9[5-14]$ & $1.06[1.04-1.08]$ & $<0.001$ \\
\hline Antidepressants ${ }^{\not}$ & $97(27)$ & $119(6)$ & $5.62[4.17-7.58]$ & $<0.001$ \\
\hline Antiretroviral treatment & $273(77)$ & $1536(80)$ & $0.80[0.61-1.05]$ & 0.10 \\
\hline Undetectable viral load & $240(67)$ & $1291(68)$ & $0.99[0.78-1.26]$ & 0.93 \\
\hline $\begin{array}{l}\text { HIV clinical stage } \\
\text { Stage A or B } \\
\text { Stage C }\end{array}$ & $\begin{array}{l}253(71) \\
103(29)\end{array}$ & $\begin{array}{l}1517(79) \\
393(21)\end{array}$ & $\begin{array}{c}1 \\
1.56[1.21-2.02]\end{array}$ & 0.001 \\
\hline HIV status disclosure & 339 (95) & $1672(88)$ & $2.77[1.68-4.59]$ & $<0.001$ \\
\hline Self perceived side-effects & $114(32)$ & $420(22)$ & $1.89[1.45-2.47]$ & $<0.001$ \\
\hline Alcohol abuse (CAGE) & $66(19)$ & $235(12)$ & $1.62[1.20-2.19]$ & 0.002 \\
\hline
\end{tabular}

${ }^{*}$ Regular benzodiazepine use was found in $356(16 \%)$ patients

${ }^{\mu}$ per one year increase

\$born outside France

\& $5 \%$ of missing data

${ }^{\mathrm{f}}$ using HADS and scoring in 3 categories, from 0 to 7 (not clinically anxious or depressive), from 8 to 10 (borderline anxious or depressive) and more than 11 (clinically anxious or depressive)

$\S$ during lifetime

${ }^{\natural}$ during the previous 4 weeks, in a medical or non-medical context 
Table 2. Predictive factors of regular BDZ use in multivariate analyses using logistic models ( $n=2138$ )

\begin{tabular}{|c|c|c|}
\hline \multirow[b]{2}{*}{ Variable } & \multicolumn{2}{|c|}{ Multivariate analysis } \\
\hline & aOR $(95 \% \mathrm{Cl})$ & $\begin{array}{c}\text { p- } \\
\text { value }\end{array}$ \\
\hline Age & $1.03[1.01-1.04]$ & 0.001 \\
\hline Living in a couple & $0.45[0.31-0.66]$ & $<0.001$ \\
\hline HIV clinical stage $\mathrm{C}$ (versus $\mathrm{A}$ or $\mathrm{B}$ ) & $1.51[1.14-2.01]$ & 0.004 \\
\hline \multicolumn{3}{|l|}{ HIV transmission group } \\
\hline Heterosexuals & 1 & \\
\hline MSM & $1.35[0.99-1.84]$ & 0.06 \\
\hline IDUs & $2.13[1.50-3.03]$ & $<0.001$ \\
\hline Migrant & $0.64[0.42-0.98]$ & 0.04 \\
\hline Suicide attempts ${ }^{\S}$ & $1.56[1.18-2.05]$ & 0.002 \\
\hline HIV status disclosure & $1.78[1.02-3.09]$ & 0.04 \\
\hline \multicolumn{3}{|l|}{ Anxiety symptoms ${ }^{f}$} \\
\hline not clinically anxious & 1 & \\
\hline borderline anxious & $2.43[1.71-3.45]$ & $<0.001$ \\
\hline clinically anxious & $6.02[4.39-8.26]$ & $<0.001$ \\
\hline
\end{tabular}

§during lifetime

${ }^{\mathrm{E}}$ using HAD scale and scoring in 3 categories, from 0 to 7 (not clinically anxious), from 8 to 10 (borderline anxious) and more than 11 (clinically anxious) 